\title{
D. Alonso Zamora Vicente (RAE, UCM), en la memoria
}

\author{
JUAN M. RIBERA LLOPIS
}

(UCM)

\section{ENCUENTRO, LAZOS CATALANES E IMPRESIONES ÚLTIMAS*}

—Cómo van las cosas por tu pueblo, bribón — preguntaba el catedrático. Y yo:

-Siguen construyendo.

-Vaya con Gandía!

-Cullera, don Alonso, Cullera... —enmendaba yo con la sorna justa del profesor ayudante. Y él sonreía, cómplice.

Pienso que don Alonso pudo errar con el topónimo de mi nacimiento, a lo sumo, un par de veces. Debía pensar que para alguien que quería adentrarse en el estudio de las letras catalanas, Gandía, ligada a March y a Martorell, era cuna más razonable. Por mi parte, quien les habla, de la Ribera Baixa del Xúquer, siempre sintió más apego por otro clásico, aquel Jaume Roig, pariente estructural de Lázaro y de quien un Excmo. D. Fernando no quería ni oír hablar. Roig, decía, si no de Cullera, hipotéticamente había nacido más cerca. Pero conste así mismo, e insistiendo en mi biografía, que no renegamos de una experiencia du-

\footnotetext{
* Cada parte de este breve díptico tuvo su particular génesis. La primera se escribió para ser leída en el Acto Homenaje a Alonso Zamora Vicente celebrado en la Casa de Galicia (Madrid, 14-III2007) y la segunda, desde Barcelona y casi en primavera, atendiendo a la solicitud del Dr. Antonio Viudas (UE, Miembro de Número de la Real Academia de las Letras y las Artes de Extremadura, Presidente de la Asociación Estudio y Divulgación del Patrimonio Lingüístico Extremeño) para incorporar nuestros recuerdos en la página dedicada al Profesor en aplex.extremadura. Con seguridad y pensadas para sendos destinos, la retórica de cada una de ellas se resiente ahora al variar su marco. No hemos querido, no obstante, corregir ni los indicios de oralidad de la primera ni el punto de intimidad de la segunda. Sólo les añadimos unos títulos que desean perfilar el contenido, parafraseando en el segundo caso, a nuestra manera, el de una colección de relatos de Alonso Zamora Vicente. Con la humilde recuperación de ambos textos, deseamos reiterar nuestro agradecimiento público a D. Alonso Zamora Vicente, también a la Dra. Carmen Mejía (UCM) por habernos llevado a esos puntos de encuentro con la memoria a un año del fallecimiento de nuestro maestro.
} 
cal, es decir gandiense. Y es que no es menos cierto que pasamos por la villa de los Borja, tiempo que quedó en buena medida bajo la tutela de un presente, Dr. D. Pablo Jauralde: él, entre otras cosas e incluida la práctica de juegos infantiles de memoria unamuniana así como de recetas culinarias del medioevo, puso en mis manos una cuidada edición de Antonio Machado y decidió que quien esto rememora debía cursar Románicas. Mi profesor de literatura española en COU, allá, en el instituto gandiense, anunció, por tanto, mis pasos hacia don Alonso, destino que, en su último trámite, contó con el buen quehacer de otro ausente, Dr. D. Pedro Peira. El Profesor Peira invitó un día a nuestro curso de la UCM al Dr. Zamora Vicente que nos sorprendió con una lección de humanidad entre coplas populares cuando nos temíamos un periplo por las fronteras dialectales. Después, otro día, el catedrático me pilló en la sala del Departamento. Creo que entonces se inició aquello de Cullera y/o Gandía. Cuando me despedí, sólo desacerté a balbucear un «adiós, don Vicente». Y de nuevo su sonrisa cómplice. Cómplice e indagante a la vez. Y digo de nuevo por que cada vez que se repetía aquel juego de lugares, él prolongaba la situación con aquella sonrisa suya que, ya desde los labios a la mirada, sellaba un pacto con cada cual a quien se la lanzaba. Pacto en el que se trenzaban aprendizajes humano y filológico ya que su sonrisa también aparecía cálida entre los momentos más serios de la lección académica.

Desde aquel Levante que hoy cuesta creer que alguna vez fuera feliz, iba y venía aquel baile de topónimos intencionadamente equivocados. Casi cada año, también, viajaron desde el litoral hacia tierra firme unas naranjas que don Alonso nos celebraba como dorados dones; y así mismo siguieron aquella ruta unas jarras de Manises, y una «rajola» setecentista que hoy sé que la sabiduría de doña M. ${ }^{\mathrm{a}}$ Josefa, su esposa, incorporó a su cocina como base de las aceiteras, y sólo muy al final un libro catalán con explícita dedicatoria a su calidad humana y a su celo por el mantenimiento de los estudios de filología catalana en la universidad madrileña. Y quedó pendiente — se nos quedó pendiente, querida Merche...- un arroz bajo el parral, entre naranjos y unos muros encalados que el tiempo y unos ocupas también se nos han llevado por delante. Desde aquel Levante..., y desde este Madrid —el que, tras el preámbulo departamental, pasó por el domicilio de Menéndez y Pelayo y después por la vivienda en la Academia y, en alguna ocasión, por El Escorial-, desde todos esos madriles fue surgiendo una guía por las letras catalanas que don Alonso tuteló con mano discreta. Aceptó mi propuesta de trabajar esa literatura; me dijo, «tu ve contándome, más aún tratándose de escritores actuales...» y él, a su vez, me paseaba por la antigua poesía lemosina y por el encuentro literario que supuso la corte napolitana del Magnànim, abrazo peninsular notificado por el Marqués de Santillana; y me hablaba de Unamuno y de Maragall, y me acercaba a nombres catalanes que habían discurrido por entre las páginas mallorquinas de los Papeles de Son Armadans de su amigo Camilo, y no dejaba de mostrar su disgusto ante ciertos desencuentros hispanos conducidos más por la política que por otros criterios, y amonestaba contra el secesionismo lingüístico valenciano, criterio de acuerdo con el cual se ratificó institucionalmente la RAE. Por este Madrid..., entre aquella periferia original y este centro de acogida pude ir haciendo los necesarios requiebros de aprendizaje histórico-literario en gran parte y quedamente tutelados 
por los Doctores Zamora Vicente y Peira Soberón. Transitaba yo por entre esa mi particular red, haciendo por cubrir de contenidos los programas de una literatura mediterránea a la postre aprendida desde la Meseta, al ritmo acompasado por las facilidades de préstamo bibliotecario que me concedía D. ${ }^{\mathrm{a}}$ Concepción Martínez y por el buen hábito pronto iniciado y continuado hasta hoy por el Dr. Juan M. González Martel de regalarme primeras ediciones - populares unas y otras no tanto- de las firmas de la Renaixença y del Modernisme. Don Alonso y, perdón por la familiaridad, Pedro, desde el romanismo ecuánime de ambos, aseguraron la presencia de los estudios de lengua y literatura catalana en la UCM mediante la primera titularidad académica fuera de los territorios lingüísticamente catalanes (1986). Si uno pudo ocuparla, sólo fue merced al destino madrileño que trazaron mis padres, al académico que pergeño el Dr. Jauralde y a la arriesgada confianza depositada en esta persona por parte de los Drs. Zamora Vicente y Peira Soberón.

Pero, ay, se supone que mi intervención debería haber tratado no tanto de mis recuerdos como de aquellos otros parámetros, a propósito de los contactos catalanes del Dr. Zamora Vicente. Pues miren, siempre sospeché que en ese sentido había acontecido algún desencuentro, así en torno a la relación con el Dr. Manuel Sanchis Guarner, pero nunca tuve el morbo de ir más allá del indicio. Nos consta, por el contrario, que D. Alonso llevó a los volúmenes de Castalia los versos de March y de Maragall en respectivas ediciones bilingües del Dr. Rafael Ferreres y del Dr. Antoni Comas. Los encuentros académicos hicieron que el Dr. Martí de Riquer y el Dr. Zamora Vicente mantuvieran un continuo contacto y cuando la edad les fue ausentando, D. Alonso preguntaba cálidamente a la Dra. Isabel de Riquer, invitada asidua a nuestros actos académicos, por su colega catalán. A través de mí, recién vuelto de Barcelona, se interesaba por el Dr. Antoni M. Badia i Margarit, ambos marcados con el tiempo por la gradual ausencia de sus compañeras de viaje. En casa de la Dra. Postigo y del Dr. Peira, de M. José y de Pedro, asistí en diferentes ocasiones y por parte del Dr. Joan Veny y del Dr. Joan Solà a la expresión del afecto y del reconocimiento de ambos por la persona y por la labor del maestro en dialectología y lexicología, a la espera del encuentro personal durante sus estancias madrileñas. Ante su fallecimiento, el IEC dirigió a la Sección de Filología Románica y a través de mi persona su pésame y el ruego de la redacción de una necrológica para su publicación Estudis Romànics, uno y otro encabezados con estas palabras: «Ens ha arribat la notícia del decés del bon amic i company Alonso Zamora Vicente. Era un home que pertot arreu deixava una estela de simpatia que, com saps, els qui el coneixíem no podrem oblidar mai.» (Barcelona, 27 de marzo de 2006, fdo. A. M. Badia i Margarit).

Para acabar. La obra filológica de Alonso Zamora Vicente perdurará tanto como los estudios de filología, lo cual no es mucho decir dada la atmósfera de nuestros campus, el perfil de buena parte de los ocupantes de sus aulas y las maquinaciones en los despachos que traman los perfiles culturales de nuestro tiempo. Como narrador, su obra está mereciendo una seria reedición. D. Alonso, además, ha contado con excelentes prologuistas - José M. ${ }^{a}$ Merino, Víctor García de la Concha, Emilia de Zuleta, José Manuel Caballero Bonald, Camilo José Cela...- - y no menos inteligentes exegetas como los aquí presentes - Carmen Mejía, Ian Michel, Pablo Jauralde, Eugenia Popeanga, Jesús Sánchez Loba- 
to- - No obstante, y cuando tanto patrimonio cultural del novecientos peligra caer en el olvido, no practiquemos con la obra de Alonso Zamora Vicente ningún tipo de ejercicio excluyente, por lo exclusivista de su tratamiento, que pudiera abocarlo a idéntico destino en esta nueva no-centuria de la desinformación mediante supuesta información acumulativa. Soy de la opinión de que ese posible tipo de actuación justifica la poca o sesgada presencia que su obra ocupa en buena parte de las monografías sobre narrativa castellana de la segunda mitad del siglo XX. Me atreveré yo, que con cautela sólo me he adentrado mediante unas puntuales líneas en su producción, a solicitar que no se caiga en la sanción de ningún acta notarial de propiedad — crítica, se entiende - sobre una obra narrativa acerca de cuyo interés quizás y también la personalidad del académico lingüista ya ha desviado parte de la atención merecida.

\section{RECUERDO CON CRISÁLIDA DENTRO}

Iniciados mis contactos con el Dr. Zamora Vicente (Don Alonso) merced a la intercesión del Dr. Peira Soberón (Pedro), sólo llegué a ser alumno de algún curso suyo ya muy tardíamente. Fue en el doctorado. Debíamos, los estudiantes por parte nuestra y bajo su tutela, fichar el léxico de ciertas colecciones de teatro popular del ochocientos. Mientras se llevaba a cabo tal labor, el catedrático y académico, desde su aura acaso intimidatoria y en las sesiones presenciales, ejecutaba su particular ejercicio docente, desconcertando al alumnado con requiebros que nada parecían tener que ver con el título del curso matriculado, con noticias literarias, tonadas del pueblo llano o rutas artesanales que escapaban a los márgenes del siglo XIX —o eso creíamos—, cruzado ese variopinto entramado de repentinas preguntas que, si atacaban a la intimidad de los presentes, pronto se redimían mediante su mirada entre pícara y sorprendentemente cómplice. Esa manera de hacer docencia se ha recordado una y tantas veces por parte de quienes fueron sus más continuados discípulos y aparece en los perfiles que han escrito del profesor; incluso el enfado que en un primer momento podía suscitar, eso hasta que su poder de seducción amansaba cualquier posible desavenencia como ha rememorado el Dr. González Martel (Juan Manuel).

Tiempo después de aquellas clases, Don Alonso nos convocó a la Dra. Mejía Ruiz (Carmen) y a mí para remover el contenido de diversas cajas en su instalación en la espléndida vivienda del último piso de la RAE, mientras Doña Concepción Martínez (Concha) llevaría a cabo la ordenación de la biblioteca que, años más tarde, pasaría a la fundación cacereña. En una de aquella cajas aparecieron las fichas estudiantiles de aquel curso, las mías sin la goma con que en su día las había sujetado, anudadas ahora por un cordoncillo de algodón quizá sacado de un costurero de su esposa (D. ${ }^{a}$ M. ${ }^{a}$ Josefa). Con un atisbo de vanidad he querido pensar mucho tiempo después, cuando no cabe sino la ausencia, que en alguna línea de los cuentos de Zamora Vicente (Don Alonso) figura una palabreja que su acerbo léxico tuvo a bien confrontar con aquella ficha de aprendiz, allí desde donde el contexto trascrito del jocoso costumbrista animó la sonrisa de Don Alonso y decidió al escritor a incorporarla, mediante una pirueta de arriesgado narrador, a uno de sus desoladores monólogos. 